\title{
AMBIÇÃO E NOSTALGIA
}

LIBERDADE,

de Franzen, Jonathan. Trad. Sergio Flaksman. São Paulo: Companhia das Letras, 2011.

FLAVIO MOURA

Mesmo antes de sair nos EUA, em setembro de 2010 , Liberdade já era objeto de atenção. O livro anterior de Franzen, As correções, de 2001 , fizera bastante barulho: ganhou, entre outros, o National Book Award, principal prêmio literário do país, e transformou Franzen numa das promessas mais auspiciosas da literatura americana. Mal começaram a sair as primeiras resenhas elogiosas de Liberdade, Oprah Winfrey incluiu-o em seu clube de leitura, o Guardian pespegou-lhe o epíteto de "livro do século" e a revista Time estampou na capa uma foto do escritor acompanhada da legenda: "O grande romancista americano".

Parte do frisson em torno de Franzen tem a ver com essa obsessão pelo "Grande Romance Americano". É um fetiche entre os autores de lá e uma espécie de santo graal da literatura:o grande autoré aquele que consegue transferir para o romance os pontos nevrálgicos da experiência do país. A trinca sagrada da prosa americana da segunda metade do século fez isso: John Updike, Phillip Roth e Saul Bellow devem boa parte de sua reputação ao modo como plasmaram a experiência dos EUA num determinado recorte de sua obra. Em As aventuras de Augie March (1953), de Saul Bellow, por exemplo, lê-se na primeira linha: "Sou americano, nascido em Chicago...". De saída estamos diante da tentativa de responder a essa pergunta: o que é ser americano?

Essa é uma tradição francesa do século XIX, a do homem de letras empenhado em responder às grandes perguntas do seu tempo. Com a transformação dos EUA em grande potência no século XX, a função se torna estratégica em face de uma experiência cuja ressonância assume escala mundial.

Franzen disputa o posto de herdeiro dessa tradição. O barulho da mídia é também reflexo da expectativa de que ele possa assumir o bastão dessa linhagem nobre em nome da nova geração. É importante lembrarque nessa transição ocorreram os atentados deı1 de Setembro. 
Nãoé, portanto, apenas o lugar do novo grande romancista americano que está vago, mas o lugar do grande romancista capaz de dar sentido a uma experiência traumática. Em certa medida, um evento como esse contribui para injetar vitalidade à atividade de escritor, de pronto convocado ao papel de intérprete de seu tempo.

É uma ideia complicada. O que se pode esperar da literatura como forma capaz de plasmar essa experiência? Como a competição com as humanidades e a indústria do cinema, da internet e da televisão interfere na capacidade da literatura em dar sentido a esse debate? Esselivro aspira à condição de grande romance, mas o frisson em seu redor, para ser compreendido, deve ser visto ao lado do prestígio alcançado pelo romance no século XIX e início do XX e da nostalgia em relação à centralidade de que já desfrutou um dia.

É simples identificar o que em Liberdade permite situá-lo como herdeiro dessa tradição. São setecentas páginas que procuram tocar os nervos da experiência americana dos últimos trinta anos. Os governos Reagan, Clinton e Bush, o terrorismo, a questão palestina, o crescimento econômico desgovernado, o aquecimento global, o conflito entre gerações, a mercantilização da cultura, a explosão do mercado financeiro, o sistema de saúde, o politicamente correto nas universidades. O cardápio é tão variado que por vezes lembra uma lista de tarefas a cumprir.

O que o salva da condição de manual é a habilidade de Franzen em atar esses temas às funções que desempenham na trama, que é bem urdida e evolui com naturalidade.

O fio é a transformação do casal Walter e Patty Berglund em ruína sentimental e moral. Ela vem de uma família liberal endinheirada de Nova York em que jamais se integrou. Não se interessava por livros ou política:era jogadora de basquetee se dedicava com ardor a isso, apesar do desprezo da mãe. Foi por ser jogadora que obteve uma vaga numa faculdade de segunda linha, em Minnesota, no início dos anos 1980.

Walter, seu colega na faculdade, era filho de pai alcoólatra e mãe trabalhadora, dona de motel de beira de estrada numa cidade do interior. Mas era o esforçado da família, o primeiro a fazer curso superior, o moço abstêmio, inábil com as mulheres e não particularmente bonito. Mas ele vence pelo cansaço, e eles se casam no fim dos anos 1980 , têm um casal de filhos e adotam uma vida de família burguesa em Minnesota.

O fator de tensão entre os dois, desde a faculdade, é Richard Katz. Richard era o melhor amigo de Walter e ao mesmo tempo seu antípoda. Era bonito, sexy e inconsequente. Walter, por outro lado, era um exemplo de lealdade e um esteio para o desregramento do colega. Desde aqueles anos, Patty cultivava uma paixão por Richard que não se concretizava em razão da lealdade entre os amigos. Resignada, Patty cedeu aos apelos de Walter menos por amor do que por falta de opção. 
Ao longo de todo o livro, Richard permanece uma sombra para o casal. Muitos anos depois, numa casa de campo, Patty e Richard passam dois dias juntos e transam, por insistência de Patty. Um pouco depois, ao cabo de anos tocando para pouca gente e amargando fracasso atrás de fracasso, Richard grava um disco de sucesso e se torna uma figura hype no mundo da música.

Os dias que Patty passa com Richard e o sucesso dele mudam tudo na vida dos Berglund. Walter, com ciúme, torna-se competitivo. Ressentido com o silêncio do amigo, que parecia se afastar dele nesse período de bonança, muda de emprego e se aproxima de políticos de má índole. Patty, depois do caso com o amigo do marido, cai em depressão.

Há ainda a relação conturbada com os filhos. Joey, o mais velho, sai de casa na adolescência para morar com a namorada, a vizinha Connie Monaghan. Isso para desespero de Patty, que odeia a mãe de Conniee sobretudo o namorado dela. O sujeito é um machão truculento, vidrado em carros, armas, e simboliza o protótipo do americano tosco, da direita mais empedernida. É essa figura que vira influência para Joey: depois de dois anos na casa do vizinho, ele vai cursar economia, sonha trabalhar em Wall Street, resgata suas raízes judaicas e vira um republicano envolvido com interesses de Bush na invasão do Iraque.

O que prende a atenção éessa espiral em direção à desintegração, ao fracasso da relação, à sucessão de passos em falso em que a vida do casal vai se transformando. A estrutura romanesca é essa. E o que Franzen consegue construir em redor dela constitui o espírito de época que o romance, de modo mais abrangente, tenta capturar em sua busca pela vaga de herdeiro da linhagem mais nobre da tradição literária americana.

A parte mais substancial é dedicada à era Bush: são os dilemas pós-11 de Setembro que aparecem com mais força e que Franzen procura examinar de modo detido. A trajetória de Joeyé exemplar disso: a descoberta do judaísmo e a vontade de explorar essa identidade vêm num contexto de reação ao terrorismo, num movimento que parece acompanhar o renascimento da direita conservadora americana logo após 2001. Sujeito oportunista, frio e incapaz de afetividade, Joey é um retrato pouco lisonjeiro dos quadros que a causa republicana é capaz de cativar.

Vale o mesmo para a onipresença do discurso ambientalista. O sarcasmo é grande e ocupa boa parte da trajetória de Walter Berglund. Desafiado pelo sucesso de Richard, Walter deixa o emprego numa unidade de conservação em Minnesota para encarar uma enrascada em Washington. Ele assume o Fundo de Conservação da Mariquita-Azul, na verdade uma grande piada. O fundo é invenção de um bilionário do Texas, amigo de Bush e Dick Cheney, interessado em vender reservas 
para empresas que exploram a extração de carvão, nocivas e poluentes. O tal fundo é uma cortina de fumaça, uma licença para destruir tendo como álibi a preservação da espécie. Ingênuo e bem-intencionado, Walter cai na arapuca - éé o nome dele que vai parar no New York Times quando fica claro o que está por trás do fundo da mariquita-azul.

Franzen é ornitólogo e adora observar pássaros, mas o ambientalismo do século XXI aparece em seu livro como tolice de gente bem-intencionada. Há acidez no modo como ele trata o discurso em defesa do controle de carbono, contra o aquecimento global e o crescimento demográfico. A crítica aos republicanos e à direita é evidente, mas também o discurso politicamente correto é alvo de sarcasmo.

A Nova York dos círculos letrados e progressistas que ele retrata, da mesma maneira, está longe de ser ambiente estimulante. Estão todos munidos de smartphones e ipods, prontos para consumir as novidades do mercado cultural sob a forma de "autenticidade" ou "atitude". O personagem de Richard Katz é o veículo das críticas disparadas ao intelectualismo bem-intencionado e ao cinismo dos liberais endinheirados nos rooftops de Tribeca e do Chelsea. Não há autenticidade possível. A decisão de Katz de voltar a ser trabalhador braçal mesmo depois do sucesso de seu disco aponta nessa direção.

Nova York é também a síntese do que Patty odeia em sua família. Democratas, judeus heterodoxos e de cabeça aberta, seus pais aparecem, logo no início do livro, a cometer uma enormidade: adolescente, Patty foi estuprada numa festa por um colega de escola. Mas o garoto era filho de doadores importantes da campanha eleitoral de sua mãe, de modo que os pais se reconciliam com a família do agressor.

Liberdade ganhou pecha de ingênuo, como se a crítica aos republicanos fizesse de Franzen um autor a serviço do bom-mocismo da era Obama. O livro não pende para um lado só do espectro político nem faz proselitismo fácil, com uma ou outra exceção, como o modo esquemático com que retrata o sistema público de saúde, pauta evidente demais nos editoriais da imprensa democrata para não esbarrar no artificialismo. Mas não é ao acusar Franzen de esquerdista ingênuo que se fará boa crítica de seu trabalho.

O ponto em discussão diz respeito à forma do livro. Desse ponto de vista, é uma obra convencional. Da mesma maneira que a imagem de "homem de letras" em nome da qual a revista Time elogiava o autor é do século XIX, também do ponto de vista formal Franzen se movimenta num registro antigo. Ele dialoga pouco com a tradição do romance do século XX. Esse é um repertório que a ele não interessou incorporar e que pode ser visto como fraqueza de certo ponto de vista crítico. Está claro, contudo, que não teria obtido essa ressonância se fosse autor de um livro experimental, e aí pode haver boa dose de cálculo. 
Há dois exemplos a esse propósito. Um é o primeiro parágrafo, cartão de visitas para qualquer obra de ficção. Outro é a maneira quase imperceptível com que tenta variar a voz narrativa em situações que a estrutura parece pedir isso. As primeiras linhas do livro dizem o seguinte:

A notícia sobre Walter Berglund não circulou localmente - ele e Patty tinham se mudado para Washington dois anos antes e já não significavam nada mais para St. Paul —, mas o povo de Ramsey Hill não era leal à sua cidade a ponto de deixar de lero New York Times. [...] Seus ex-vizinhos tiveram dificuldade em conciliar os adjetivos com que o Times o qualificava ("arrogante", "presunçoso", "eticamente comprometido") como vizinho generoso, sorridente e corado que viam pedalando até a condução para o trabalho todo dia [...] Se bem que sempre tinha havido algo estranho na família Berglund.

Esse primeiro parágrafo é poderoso. Todas as setecentas páginas seguintes são dedicadas a mostrar como se deu essa queda que levou a família exemplar até as páginas de escândalo do Times, coisa que só acontece ao fim do livro, quando Walter atua como laranja dos republicanos interessados na extração de carvão. Mas é também um truque romanesco dos mais convencionais: o autor puxa um elemento decisivo do fim da história para as primeiras linhas, de modo a prender a atenção do leitor até que essa isca, lançada logo de início, se mostre em sua totalidade.

Vale comparar com uma abertura célebre, a de Anna Karenina, de Tolstói:

Todas as famílias felizes se parecem entre si; as infelizes são infelizes cada uma àsua maneira.

Na segunda linha, já se sabe que o narrador vai passar as páginas seguintes a contar uma desgraça familiar. Mais que isso: uma desgraça particular, que só poderia ter sido vivida daquela maneira.

Não é casual a comparação com Tolstói. Algumas páginas de Liberdade são dedicadas a paráfrases de Guerra e paz, que Patty lê em seu retiro na casa de campo. Como nos grandes livros de Tolstói, em Franzen o centro é também o drama familiar. Assim como na obra do escritor russo, há uma capacidade de conferir humanidade aos personagens que porvezes parece suspender a mediação do autor, como se a própria realidade se escrevesse de forma espontânea diante de nossos olhos.

As variações da voz narrativa são uma fragilidade mais evidente. Franzen sabe bem que o romance contemporâneo não pode prescin- 
dir de questionamento sobre a forma de narrar. Compõe seu livro, assim, a partir de dois narradores: um é onisciente, em terceira pessoa, bem aos moldes do romance do XIX. Outros trechos, contudo, são narrados por Patty Berglund. Por sugestão de seu terapeuta, ela escreve uma autobiografia, que faz as vezes de segundo capítulo e ocupa cento e tantas páginas.

É de estranhar a pequena variação entre os trechos do narrador convencional e aqueles narrados por Patty. Ela também escreve em terceira pessoa, com raras referências à "autobiógrafa". Eescreve com brilho, com passagens que funcionam nas mãos de um escritor de talento como Franzen, mas que não convencem quando se tem em mente que a voz é de uma dona de casa deprimida e ex-jogadora de basquete. Franzen tenta marcar a diferença: assim que acaba a autobiografia, entram parágrafos imensos, sem ponto final, como a indicar essa mudança. Mas são ocorrências episódicas, que não marcam o andamento do texto e deixam essa incompletude no ar.

Franzen não é um romancista acabado é saudável desconfiar da histeria em torno de seu livro. Mas isso não é o mesmo que lhe negar os méritos. Há um lugar vago para o grande intérprete literário da alma americana pós-11 de Setembro. O escritor que der sentido a ela por meio de uma imagem forte como a da família Berglund terá decerto destaque merecido.

É cedo para dizer se Franzen éessa figura, mas está sem dúvida entre aqueles capazes de aspirara essa condição. Suas ambições de sero Tolstói do século XXI podem suscitar desconfiança quanto à capacidade de renovar a forma do romance e também sugerem pouca disposição para uma discussão necessária sobre o papel que cabe hoje à ficção literária. Mas a intensidade com queessas ambições são praticadas em seus livros é rara e digna de nota. E elas só podem fazer bem para a literatura num momento em que sua morteé decretada a cada dia.

FLAVIO MOURA é sociólogo. 